\title{
A PARCERIA ENTRE UNIVERSIDADE E ESCOLA NO ESTÁGIO SUPERVISIONADO: A EXPERIÊNCIA EM QUEBEC
}

\author{
SCHOOL-UNIVERSITY PARTNERSHIP IN THE SUPERVISED \\ PRACTICE: THE QUEBEC EXPERIENCE
}

\section{LA ALIANZA ENTRE UNIVERSIDAD Y ESCUELA EN LAS PRÁCTICAS SUPERVISADAS: LA EXPERIENCIA EN QUEBEC}

\author{
Dijnane Vedovatto ${ }^{11}$ \\ https://orcid.org/0000-0002-7435-6849 \\ Cecília Borges ${ }^{2}$ \\ https://orcid.org/0000-0001-8198-9743
}

\footnotetext{
${ }^{1}$ Universidade Federal de São Carlos, São Carlos, São Paulo - Brasil. E-mail: dijnane@ ufscar.br.

${ }^{2}$ Universidade de Montreal, Quebec - Canadá. E-mail: cecilia.borges@ umontreal.ca.
}

\section{Resumo}

As parcerias entre universidade e escola são importantes para o desenvolvimento dos estágios na formação de professores. Porém, no Brasil há muitas fragilidades sobre isso, embora se observem algumas iniciativas exitosas em parceria. Experiências internacionais revelam avanços nessa questão, em especial no caso de Quebec, que, com base no modelo profissional de formação, possui um Centro de Formação Inicial de Mestres (CFIM), no qual o estágio supervisionado tem destaque para a formação de professores. O objetivo foi compreender, no caso de Quebec, a parceria entre universidade e escola nos estágios. O quadro teórico se pauta na profissionalização dos professores. A pesquisa qualitativa é um estudo de caso, do tipo intrínseco. Para coleta de dados foram feitas entrevistas semiestruturadas com coordenadores de programas de formação da universidade canadense. Os resultados indicam uma estrutura que favorece a parceria entre universidade e escolas, fruto de uma política de formação docente. Alguns elementos do trabalho desenvolvido em Quebec podem inspirar reflexões sobre as possibilidades de trabalho no contexto de formação docente no Brasil, visando uma política na qual os estágios adquiram maior centralidade na formação de professores.

Palavras-chave: Formação de professores. Estágios supervisionados. Universidade e escola.

\footnotetext{
${ }^{1}$ Este trabalho contou com o apoio da FAPESP (Fundação de Amparo à Pesquisa do Estado de São Paulo), processo $n^{\circ} 2015 / 26428-2$.
} 


\begin{abstract}
Despite the importance of partnerships between universities and schools for teacher internship programs, such an initiative shows considerable weaknesses in Brazil. International experiences show advances in this matter, especially the Quebec case - which includes a Teacher Training Center (CFIM) based on the professional training model whereby teacher training plays a key role in supervised internship. This study sought to understand the school-university partnership in supervised practice in Quebec, considering teachers' professionalization. This qualitative research consists of an intrinsic case study conducted with data collected by means of semi-structured interviews with coordinators of training programs at the Canadian university. The results indicate a teacher training policy that favors partnership between universities and schools. Some elements of the work developed in Quebec can stimulate reflections on work possibilities in the context of teacher training in Brazil, aiming at a policy that grants greater centrality to internships in teacher training.
\end{abstract}

Keywords: Teacher training. Supervised internships. Partnership. School and university.

\title{
Resumen
}

La alianza entre universidad y escuela es importante para el desarrollo de pasantías en la formación del profesorado. Sin embargo, en Brasil hay muchas debilidades al respecto a pesar de que existen algunas iniciativas exitosas. Las experiencias internacionales revelan avances, en particular en el caso de Quebec (Canadá), que, desde el modelo de formación profesional, cuenta con un Centro de Formación de Profesores (CFIM) en el que se destaca la pasantía supervisada para la formación del profesorado. Este artículo tuvo por objetivo comprender la alianza entre universidad y escuela en las pasantías en Quebec. El marco teórico se basa en la profesionalización del profesorado. Este es estudio de caso, cualitativo, de tipo intrínseco. Para la recolección de datos, se realizaron entrevistas semiestructuradas con coordinadores de programas de capacitación en la universidad canadiense. Los resultados indican que la estructura favorece la alianza entre universidades y escuelas, como resultado de una política de formación docente. Algunos elementos del trabajo desarrollado en Quebec pueden inspirar reflexiones sobre las posibilidades de trabajo en el contexto de la formación docente en Brasil, apuntando a una política en la que las pasantías adquieran mayor centralidad.

Palabras clave: Formación docente. Pasantías supervisadas. Escuela y universidad.

\section{Introdução}

A parceria entre universidade e escola para o desenvolvimento dos estágios é extremamente importante para que ocorra um trabalho conjunto entre as instituições formativas; porém, para a sua efetivação, há muitos desafios a serem enfrentados. No Brasil, as parcerias entre as instituições são frágeis e há pouca clareza sobre os papéis dos agentes no 
desenvolvimento dos estágios de formação docente (CYRINO, 2016; CYRINO; SOUZA NETO, 2017; VEDOVATTO IZA; SOUZA NETO, 2015).

Embora haja alguns esforços no sentido de se colocar a prática em evidência, sobretudo no estabelecimento de parcerias entre universidade e escola para o desenvolvimento dos estágios supervisionados (BRASIL, 2002a, 2002b), Gatti, Barreto e André (2011, p. 114) problematizam que a "relação teoria e prática tão enfatizada em documentos e normas, com a concepção curricular integrada proposta, não se concretizam no cotidiano das diferentes licenciaturas".

Em outro texto, Gatti (2013, p. 58) se torna mais enfática ao colocar que se pode sintetizar a formação de professores no Brasil como "apresentando currículos fragmentados, com conteúdos excessivamente genéricos e com grande dissociação entre teoria e prática, estágios fictícios e avaliação precária, interna e externa". Cabe aqui ressaltar que tem havido um mercado da formação que visa criar "caminhos alternativos" (NÓVOA, 2017, p. 5) para a formação inicial, e que vai à direção contrária ao que é defendido sobre a profissionalização do ensino.

É necessário que sejam criadas articulações profundas entre teoria e prática durante todo o processo formativo, e que este absorva "a dimensão experiencial, não mais separando teoria e prática, mas mergulhando, desde o início, o estudante e o formador em situação de mediação dos confrontos da prática, buscando significação das teorias" (FRANCO, 2008, p. 123).

Nessa direção, a Resolução do Conselho Nacional de Educação (CNE), Conselho Pleno (CP) no 2/2015 (BRASIL, 2015, p. 4), que define as Diretrizes Curriculares Nacionais para a formação inicial dos cursos de licenciatura, indica que deve haver uma "articulação entre a teoria e a prática no processo de formação docente, fundada no domínio dos conhecimentos científicos e didáticos" (BRASIL, 2015, p. 4). Essa ideia permaneceu na Resolução CNE/CP n2/2019 (BRASIL, 2020, p. 4), que coloca a centralidade da prática por meio de estágios, de modo que "enfoquem o planejamento, a regência e a avaliação de aula, sob a mentoria de professores ou coordenadores experientes da escola campo do estágio, de acordo com o Projeto Pedagógico do curso". Para isso, o documento aponta para o "estabelecimento de parcerias formalizadas entre as escolas, as redes ou os sistemas de ensino 
e as instituições locais para o planejamento, a execução e a avaliação conjunta das atividades práticas previstas na formação do licenciando" (BRASIL, 2020, p. 4).

O Plano Nacional de Educação (BRASIL, 2014) prevê diferentes metas e estratégias a serem efetivadas no período de 2014 a 2024, visando fortalecer a profissão docente e a formação inicial. Entre os descritores de uma política de formação inicial está o de "valorizar as práticas de ensino e os estágios nos cursos de formação de nível médio e superior dos profissionais da educação, visando ao trabalho sistemático de articulação entre a formação acadêmica e as demandas da educação básica" (BRASIL, 2014, meta 15, estratégia 15.8). Há a perspectiva de valorização dos profissionais da educação e, em especial, do estágio supervisionado nos cursos de licenciatura, na qual a articulação entre a formação de professores e as escolas da rede pública aparece como central nesse processo.

Embora tenha havido esforços para favorecer uma maior articulação entre universidade e escola, visando uma parceria efetiva, os trabalhos concretizados são bastante escassos. Ainda que a produção das pesquisas sobre o assunto seja numerosa e bastante significativa, o que tem sido constatado na prática, com algumas exceções, é um distanciamento entre a formação de professores e a escola. A formação inicial de professores tem sido questionada em função de certo descuido com os estágios (GATTI et al., 2019). Gatti et al. (2019) afirmam que as práticas integradas às disciplinas curriculares são recomendadas desde o início da formação docente em diversos países, porém há uma ausência de informações que indiquem como isso se realiza no cotidiano dos cursos.

Com base na identificação de que os estágios nos cursos de formação de professores no Brasil têm fragilidades com relação às parcerias entre universidade e escola, e de que há experiências internacionais de estágio na formação de professores em processo avançado, emerge esta pesquisa. Assim, o objetivo deste trabalho foi compreender, no modelo profissional de formação de Quebec, a parceria entre universidade e escola nos estágios supervisionados na formação de professores.

\section{A profissionalização}

No final dos anos 1980, alguns países passaram por importantes reformas na educação, que tinham como proposta o movimento de profissionalização do ensino, no qual se visava 
tornar a atividade de ensino uma profissão (SOUZA NETO; CYRINO; BORGES, 2015). Maués (2003) afirma que as reformas educacionais ocorridas no final da década de 1980 partiram de mudanças impostas pela globalização, o que exigia maior eficiência e produtividade dos trabalhadores, com o propósito de se adaptarem às exigências do mercado.

A elaboração do relatório Tomorrow's Teachers, pelo Holmes Group (1986), foi um marco importante nesse processo, pois propõe a formação de professores estruturada a partir da carreira docente, baseada na idéia de profissão. Desse modo, na medida em que o docente avança no tempo de carreira, vai gradativamente assumindo o lugar de um professor, pois são profissionais que se formam com conhecimento científico, com base na análise reflexiva e crítica da prática profissional (HOLMES GROUP, 1986). O Holmes Group (1986) propôs uma reforma na formação docente tendo a profissionalização como objetivo, e, para isso, a necessidade de uma base de conhecimentos próprios dos professores.

As reformas educacionais que possuem um caráter internacional, tendo a globalização como algo comum, têm a tônica na formação de professores como uma maneira de enfatizar a importância do desempenho educacional, visando o crescimento econômico, o que em princípio depende da atuação dos profissionais da educação. Desse modo, a "universitarização" seria um modo de qualificar a formação e encaminhar para a profissionalização, o que significa um maior aprofundamento dos conhecimentos e, portanto, maior domínio no exercício profissional (MAUÉS, 2003).

A profissionalização pode ser definida em função de compreender aspectos relacionados à organização social de um conjunto de atividades, o qual consiste no reconhecimento social de sua utilidade. Além disso, a profissionalização envolve também os saberes e competências necessários para o exercício profissional; melhores condições de trabalho e maior exigência da formação para o exercício profissional; o que demanda a profissionalização das organizações na formalização de um sistema de expertise (TARDIF, 2012; TARDIF; LESSARD, 2009; WITTORSKI, 2014).

No processo de profissionalização há a necessidade de considerar dois movimentos: de um lado, "uma maior proximidade da formação com as práticas profissionais docentes, com a consideração da escola como lócus formativo privilegiado"; e, de outro, "a elevação do nível de certificação dos professores acompanhando a elevação do nível educacional da população" (SARTI, 2013, p. 218). 
Assim, a formação docente passa a ser compreendida como

\begin{abstract}
um processo de socialização, que deve possibilitar ao sujeito organizar os saberes aprendidos para serem empregados em situação de ensino [...] [envolvendo uma]integração entre o local de trabalho e a formação docente [...][, pois a]escola, enquanto espaço onde os saberes docentes são mobilizados, passa a ser considerada central para a formação do magistério, enquanto se espera que os professores experientes assumam uma nova identidade profissional, como formadores de seus pares[, seguindo uma lógica socioprofissional]. (SARTI, 2013, p. 218)
\end{abstract}

Nóvoa (2009) defende a necessidade de que a formação dos professores seja construída dentro da profissão. Ele propõe que a formação de professores seja centrada na aprendizagem dos alunos, no sentido de estudar casos concretos do trabalho escolar, de passar para dentro da profissão, visando a aquisição de uma cultura profissional.

De acordo com o autor, é preciso criar um novo lugar institucional, no qual haja a ligação entre a universidade e um conjunto de escolas de educação básica, mas para isso é preciso juntar escolas e universidades dispostas a construir processos de formação cujas bases estejam vinculadas a uma transição entre a formação e a profissão (NÓVOA, 2019).

Nessa direção, o meio escolar é considerado fundamental para a formação e atuação profissional. O local de trabalho e a formação são elementos essenciais para se efetuar a profissionalidade docente, pois "a visão profissional enseja a uma recentração da formação sobre a prática, e tem como consequência deslocar uma parte da formação para o lugar do exercício profissional” (GERVAIS; DESROSIERS, 2005, p. 1).

Os estágios curriculares supervisionados se configuram como o lugar em que pode haver grande aproximação entre a formação e a prática profissional, no qual o futuro professor poderá ter amplo conhecimento sobre o trabalho desenvolvido nas escolas, possibilitando a constituição de uma visão sobre o campo profissional.

\title{
3 Estágio curricular supervisionado
}

O estágio supervisionado é entendido como um período em que o aluno/estagiário irá aprender elementos constitutivos de uma determinada profissão, observando-se que, nos 
cursos de formação de professores, essa prática profissional deveria proporcionar conhecimentos para a atuação na educação básica.

Assim, espera-se que haja envolvimento entre o professor (da escola), o estudante estagiário e o professor formador (da universidade), para que o estágio seja efetivamente significativo para o futuro professor, pois é o "componente curricular estruturador da formação docente, numa perspectiva de trabalho coletivo", e que tem como propósito "favorecer uma participação de caráter recíproco, com vistas à construção do conhecimento e à promoção da profissionalização do estagiário" (AZEVEDO, 2009, p. 32).

Giglio (2010) assinala que temos de enfrentar o desafio da revisão do modelo de formação prática, pois os estagiários deixaram de promover uma observação criteriosa de interrogação da realidade, no sentido de buscar compreender a complexidade que habita as relações no interior da escola.

Sarti (2009) afirma que, no Brasil, as instituições formadoras de professores não mantêm um trabalho conectado com as escolas de educação básica que acolhem os estagiários, apesar de haver orientações legais a esse respeito. Vedovatto Iza e Souza Neto (2015) também identificam os desafios a serem enfrentados no que se refere às articulações entre universidade e escola, e indicam maior atenção para os estágios docentes.

Cyrino e Souza Neto (2014) destacam trabalhos de estágio nacionais e internacionais com experiências de aproximação, colaboração e parceria entre escola e universidade, e enfatizam que a relação entre universidade e escola é permeada pelo modelo de formação. Nas experiências internacionais, a escola é considerada como um lugar de formação, porém no Brasil há um discurso "sobre a formação, a escola e o estágio, padecendo na dimensão crítica, muitas vezes acrítica ao não tratar de fato da formação de professores" (CYRINO; SOUZA NETO, 2014, p. 106). Os autores enfatizam que "padecemos em não considerar a prática e a prática profissional como um lugar de formação e de produção de conhecimento" (CYRINO; SOUZA NETO, 2014, p. 106), e indicam a necessidade de mudança de mentalidade com relação a essa questão.

No âmbito internacional há experiências que apontam avanços com relação ao estabelecimento de parcerias no estágio. Em Quebec, no Canadá, o Ministério da Educação investiu nas escolas para acompanhamento dos estágios em relação à recepção, supervisão e avaliação dos formandos. O curso de formação de professores da universidade canadense 
enfatiza o profissional reflexivo, que produz saberes e delibera sobre a própria prática. Para compreender esse processo, foram realizados os procedimentos metodológicos descritos a seguir.

\section{Procedimentos metodológicos}

Esta pesquisa de natureza qualitativa tem como proposta o contato direto com o ambiente e as questões afetas ao problema a ser investigado, envolvendo o trabalho de campo, com descrições de um determinado contexto (LUDKE; ANDRÉ, 2001). É um estudo de caso que tem como característica o interesse em uma determinada instituição, em que se intenciona conhecer em profundidade as situações que ocorrem nela (ANDRÉ, 2000).

O estudo de caso do tipo intrínseco permite compreender as interações de um grande número de fatores, bem como a complexidade e riqueza dos contextos educacionais, nos quais se busca compreender as particularidades de um determinado fenômeno (KARSENTI; DEMERS, 2011).

O caso do modelo de formação profissional de Quebec foi o foco desta pesquisa, visando compreender os elementos que evidenciam a política docente de formação de professores no estágio, na articulação entre a universidade e as escolas.

A escolha desta instituição se deu em função de a formação de professores estar pautada no modelo profissional de formação. Para coletados dados, foram realizadas entrevistas semiestruturadas ${ }^{2}$ e análise documental ${ }^{3}$ de documentos referentes aos estágios na formação de professores de Quebec. É importante ressaltar que esta pesquisa foi submetida e aprovada pelos comitês de ética ${ }^{4}$ das universidades brasileira e canadense.

\subsection{Entrevistas semiestruturadas}

Para a coleta de dados, foram realizadas entrevistas semiestruturadas a partir de um roteiro com 16 perguntas previamente estabelecidas e distribuídas em três blocos de questões.

\footnotetext{
${ }^{2}$ As entrevistas foram realizadas apenas com os professores coordenadores de estágios, e não foi possível realizar entrevistas com os professores das escolas e estagiários da universidade pesquisada.

${ }^{3}$ Os documentos analisados neste trabalho se referem às diretrizes nas quais o Ministério da Educação apresenta as orientações para a formação de professores de Quebec.

${ }^{4}$ Parecer n ${ }^{\circ} 1.610 .854$, Comitê de Ética em Pesquisa. 
O primeiro bloco, denominado "Formação profissional (inicial e continuada) e acompanhamento ou supervisão de estagiários", tinha quatro questões; o segundo bloco, denominado "Dispositivos de acompanhamento de estagiários e papel dos supervisores e professores colaboradores", continha seis questões; e, por fim, o terceiro bloco, "Universidade e escola", seis questões.

Todas as entrevistas foram realizadas individualmente, em local, data e horário estabelecidos pelos entrevistados, com um tempo médio de 50 minutos cada uma. Todas as entrevistas foram gravadas em áudio, por meio de um aparelho celular, e, depois, foram transcritas e traduzidas para o português, para análise do material.

A seguir, os participantes da pesquisa.

\subsection{Os participantes da pesquisa}

Participaram da pesquisa quatro coordenadores de estágio ligados ao Centro de Formação Inicial de Mestres (CFIM), conforme o Quadro 1.

Quadro 1 - Participantes da pesquisa

\begin{tabular}{|l|l|}
\hline Participante & \multicolumn{1}{c|}{ Atuação } \\
\hline PCA & Coordenadora dos estágios pré-escolar e educação primária. \\
\hline PCJ & Responsável pelos estágios em adaptação escolar. \\
\hline PCM & Responsável pedagógico de estágio em francês. \\
\hline PCG & $\begin{array}{l}\text { Coordenadora educacional dos estágios dos diversos programas de } \\
\text { estágio. }\end{array}$ \\
\hline
\end{tabular}

Fonte: Elaborado pelas autoras.

Para garantir o sigilo dos participantes desta pesquisa, os professores coordenadores serão identificados pela sigla $\mathrm{P}$ (professor), C (coordenador) e uma letra aleatória. Os dados foram organizados, sistematizados e analisados tendo como foco o objetivo deste estudo. 


\section{A formação de professores em Quebec}

O movimento de profissionalização pode ser verificado no reconhecimento da docência como uma profissão, bem como da complexidade que envolve o exercício profissional docente, com valorização e reconhecimento social, que exigem uma formação comprometida e responsável.

O referencial de competências profissionais da docência, que se constitui como o documento oficial do Ministério da Educação do Quebec, foi feito com consulta a diversos parceiros da educação e tem como objetivo preparar os futuros professores para cumprir as ações de caráter profissional em benefício de todos os estudantes do Quebec. Esse documento dá base a todos os programas de formação docente, e visa atender um nível de competência elevada ao final de sua formação profissional (GAUTHIER; RAYMOND; MARTINET, 2001).

Tardif (2000, p. 8) afirma que todos os esforços realizados nos últimos 20 anos, visando a construção de um repertório de conhecimentos, vão à direção de "fixar padrões de competência para a formação dos professores e para a prática do magistério. Se esses esforços e reformas forem bem-sucedidos, o ensino deixará, então, de ser um ofício para tornar-se uma verdadeira profissão".

A profissionalização é o que baliza as ações voltadas para a formação de professores, e é importante ressaltar que isso é claro nos documentos relacionados com os estágios. Desse modo, a profissionalização na universidade pesquisada está ligada à ideia do desenvolvimento e da construção de competências necessárias ao exercício de uma profissão, e tais competências se manifestam nas ações de um determinado grupo.

Na experiência de Quebec, há a contratação de professores associados, que recebem os estagiários em sua sala de aula, além de terem uma formação oferecida pela universidade e receberem um apoio financeiro para orientar os alunos estagiários como parte de seu trabalho. Essa iniciativa ocorreu após uma reforma no programa de formação de professores no início dos anos 2000, em que foram propostas 700 horas de estágio supervisionado pelo Ministério da Educação do Quebec. Neste processo, houve um investimento nas escolas para acompanhamento dos estágios em relação à recepção, supervisão e avaliação dos formandos. 
Nessa direção, as universidades deveriam: assegurar uma formação para o ensino de caráter profissional; repartir o mínimo de 700 horas de estágios ao longo da escolarização; assegurar experiências diversificadas aos estudantes; promover o desenvolvimento de competências para cada perfil profissional; desenvolver colaboração entre universidade e escola; e reconhecer o papel "fundamental dos professores primários e secundários, particularmente os mais experientes, na supervisão e enquadramento dos estudantes estagiários, futuros professores" (BORGES, 2008, p. 154-155).

A partir dessas premissas, a Faculdade de Ciências da Educação da Universidade de Montreal criou o CFIM, no formato de um departamento, com o propósito de garantir a formação prática em relação aos estágios. O CFIM é responsável por toda a gestão e negociação realizada com os agentes do meio escolar.

É importante ressaltar que o Ministério da Educação ofereceu um significativo suporte para "formar os professores associados à supervisão e ao acompanhamento pedagógico dos estagiários e para cobrir os custos de liberação do professor associado de uma parte de suas tarefas de ensino" (BORGES, 2008, p. 155), visando a formação de futuros docentes.

Uma remuneração é atribuída para as escolas que acolhem os estagiários, de maneira que permite oficializar o engajamento dos professores, pois há o reconhecimento do seu tempo dedicado às atividades com os estagiários (GERVAIS, 2013).

\section{Centro de Formação Inicial de Mestres (CFIM)}

O CFIM é responsável por toda a gestão e negociação realizada com os agentes do meio escolar. Há uma valorização dos professores da escola, que promovem a formação dos futuros professores; assim, a formação ocorre tanto em meio universitário quanto em meio escolar, e segue em alternância durante todo o percurso de formação docente. Nesse contexto, a escola tem grande importância para a formação de professores (GERVAIS; DESROSIERS, 2005), e o estágio ganha centralidade ao promover a articulação entre todos os agentes envolvidos nesse processo.

O modelo profissional de formação, que é fruto de uma política de formação profissional docente, pode ser observado por meio das ações do CFIM, que gerencia todos os registros dos alunos, tendo atualmente mais de 2 mil estudantes sob sua responsabilidade, de 
modo que é um departamento que lida com o "progresso dos estudantes em seu programa" (PCG).

O CFIM tem o "papel de orientar programas de graduação para os alunos que estão em formação inicial de professores" (PCA), e também de "encontrar lugares de estágio para os alunos, além de treinamento para os supervisores de estágio para cada ano" (PCJ).

Em relação ao funcionamento do CFIM, há encontros "que visam uma atualização sobre os problemas encontrados, as coisas diferentes que queremos mudar, projetos específicos, e nós tentamos organizar para que possam ser consistentes" (PCA). Desse modo, há toda uma "distribuição de lugares de formação e a ligação com os conselhos escolares para realmente ter certeza de que continuamos a ter uma parceria com escolas que sejam lugares para onde enviar os nossos alunos de estágio" (PCA).

A parceria com as escolas, identificada nos resultados da pesquisa, vai ao encontro de que "a profissionalização de professores implica a obtenção de um espaço autônomo, próprio à sua profissionalidade, com valor claramente reconhecido pela sociedade" (GATTI, 2010, p. 1356). Além disso, o CFIM tem um importante trabalho de formação profissional, pois são "os profissionais que cuidam de formação que fazem a ligação com os conselhos escolares, porque é realmente especial, para o curso, estar em contato com as escolas" (PCA). Percebese, aqui, a ênfase nas escolas como um lugar de formação e o cuidado em relação aos professores que recebem os estagiários nas instituições de ensino.

A formação dos professores é uma ação proveniente de uma política de formação inicial e continuada, pautada no modelo profissional de educação, cujo foco é o aumento da qualidade da formação, bem como um aprofundamento sobre os saberes na sua base.

Nóvoa (2009) afirma que é preciso passar a formação de professores para dentro da profissão, e defende estudos de casos escolares, sobretudo os de insucesso, para, diante disso, produzir uma análise coletiva das práticas pedagógicas, havendo persistência profissional para responder às necessidades dos alunos, bem como compromisso social e desejo de mudança. Assim, a formação de professores pautada nas próprias práticas é um dos elementos basilares da profissionalização docente (MAUÉS, 2003; TARDIF, 2000).

De acordo com Nóvoa (2019), o período de transição entre a formação e a profissão é fundamental no processo de tornar-se professor. O referido autor sugere um "tempo entre - 
dois", entre o fim da formação e o início da profissão, no qual haja a "responsabilidade das direções das escolas e dos professores mais experientes quanto ao acolhimento e acompanhamento dos seus jovens colegas" (NÓVOA, 2019, p. 200). Essa ideia perpassa uma parceria afinada entre universidade e escola, pois cada instituição assume um papel nesse processo, mas ao mesmo tempo conjuntamente visam a formação do professor.

No caso do CFIM, há a oferta de uma formação para os professores que recebem os estagiários, e as condições para que ela aconteça são propícias em função de um investimento do Ministério da Educação, pois as "universidades oferecem formações aos professores associados. Os professores não são obrigados a acompanhar a formação, mas as universidades são obrigadas a desenvolver programas e a oferecer os programas” (PCG).

As condições para se fazer a formação provêm de uma política de formação continuada que permite que ela aconteça, de modo que há um incentivo para que os professores a façam, pois "há a ajuda do Ministério da Educação, então, quando uma comissão escolar recebe um estagiário, há uma alocação que é vertida para a comissão escolar" (PCG), e com isso é possível "liberar o professor para trabalhar com o estagiário em certos momentos. Então, isso favorece muito a formação, porque nós temos condições para o fazer. [...] A grande maioria dos professores atualmente pode receber essa formação, e isso faz uma diferença" (PCG).

Aos professores colaboradores é confiada uma parte importante da formação de seus futuros colegas, não somente porque os estágios têm grande importância nos programas, mas por terem um papel reconhecido a título de uma verdadeira parceria na formação.

Para um maior compromisso em relação à formação em ambiente profissional, foram tomadas algumas medidas governamentais, como: pagamento aos professores por acolherem os estagiários; inclusão da formação nas tarefas dos professores; e estabelecimento de responsabilidade para que os comitês escolares colaborem na formação de futuros docentes.

Há um comprometimento em relação às condições para que a formação aconteça, a qual é demandada para as universidades, mas ao mesmo tempo é também propiciada uma estrutura que favorece essa formação, pois "um elemento importante foi que o Ministério pediu às universidades que os estágios tenham muita importância, e é preciso que os professores sejam formados para receber os estagiários" (PCG). 
Além dessa estrutura, há também um compromisso profissional dos professores, pois eles têm como principal motivação se manterem informados sobre o que está acontecendo na área,“porque receber formação é ter alguém que ainda está na faculdade, que ensina o mais recente de ensino, avaliação da escola e assim por diante [...]. É uma forma de educação continuada, se você vai receber um estagiário" (PCG).

Há um compromisso do professor para com a sua profissão e, ao se referir às qualidades da profissionalidade docente, Contreras (2002, p. 74) ressalta que o direcionamento adequado à realização do bom ensino abarca "dimensões do seu fazer profissional no qual se definem aspirações com respeito à forma de conceber e viver o trabalho de professor, ao mesmo tempo em que se inscreve a forma de dotar a realização do ensino de conteúdo concreto".

O compromisso profissional pode ser evidenciado quando os professores que recebem estagiários dizem: "Eu quero dar de volta o que alguém me deu quando eu me formei; por isso estou feliz de formar alguém que um dia vai ser meu amigo ou meu colega" (PCG). Tal fala nos permite identificar o sentimento de pertença profissional e consciência de ser formador no processo formativo de um colega mais jovem.

Wittorski (2014) afirma que a profissionalização envolve autonomia e especificidade de um conjunto de atividades, e ao mesmo tempo se caracteriza por um processo de formação de indivíduos para os conteúdos de uma profissão. Outro aspecto da profissionalidade é o que Contreras (2002) chama de compromisso ou obrigação moral, pelo qual o professor está comprometido com os seus alunos em relação ao seu desenvolvimento enquanto pessoas; apesar das tensões e conflitos inerentes a esse trabalho, há a necessidade de se atender ao avanço nas aprendizagens das pessoas com as quais se trabalha.

A profissionalidade docente relaciona-se com a comunidade social da qual os professores fazem parte e na qual realizam sua prática profissional. "A educação não é um problema da vida privada dos professores, mas uma ocupação socialmente encomendada e responsabilizada publicamente" (CONTRERAS, 2002, p. 79).

Nessa direção, a profissionalização pode ser identificada também nos acordos relacionados ao estágio, pois eles são institucionais, e seguem regras que são estabelecidas em reuniões chamadas "mesas de diálogos”, que ocorrem na maior parte das regiões de Quebec, agrupando representantes das universidades, das escolas e das direções regionais do 
Ministério da Educação. Os encontros regulares incluem os representantes dos sindicatos e das direções escolares, permitindo as trocas para a distribuição dos estágios e o estabelecimento dos critérios de seleção de professores associados, de formação de professores para o acompanhamento de estagiários, e igualmente um melhor conhecimento e compreensão das demandas recíprocas, dos contextos respectivos dos parceiros, e o estado de progresso das reformas em curso.

Essa estrutura define as regras para o funcionamento dos estágios, pois as reuniões envolvem representantes que estão diretamente envolvidos com os trabalhos de formação de professores no CFIM. Nas mesas de diálogos, os profissionais "discutem os estágios e agrupam as pessoas das universidades da Grande Montreal, e nós discutimos as problemáticas que são realizadas nos estágios, mas que concernem a todo mundo" (PCA).

As reuniões coletivas indicam a colaboração entre os diferentes profissionais engajados na formação inicial e continuada, de modo que há um diálogo visando um objetivo comum. Na formação inicial, a profissionalização do ensino tem $\mathrm{o}$ foco sobre $\mathrm{o}$ desenvolvimento de competências profissionais, o que exige uma grande articulação e colaboração entre os diferentes formadores envolvidos na formação inicial (BORGES, 2011).

Contreras (2002, p. 79) afirma que as práticas profissionais não devem se constituir como isoladas, mas sim partilhadas, já que somente nos contextos "sociais, públicos, a obrigação ética pode alcançar sua dimensão adequada", e se referem ao contexto profissional em que as

associações de professores, seja em seus próprios centros ou em outros âmbitos de agrupamentos e organização, desenvolvem sua profissionalidade na medida em que compartilham problemas, discutem princípios, contrastam alternativas e soluções, analisam os fatores que condicionam seu trabalho, organizam sua ação etc.

É importante destacar que as reuniões entre todos os envolvidos com os estágios são essenciais para regrar as ações que são realizadas nos estágios, e que, portanto, envolvem todas as instituições e profissionais diretamente relacionados com a formação.

As informações apresentadas podem nos indicar que o estágio é uma responsabilidade institucional conjunta, advinda de uma política de formação que tem em sua base a profissionalização do ensino como um objetivo comum das instituições parceiras. Portanto, há 
uma estrutura e organização que favorecem a realização das parcerias entre universidade e escolas, pautadas na profissionalização, na qual a formação inicial e continuada é de grande importância.

\section{Considerações finais}

$\mathrm{O}$ contexto de formação docente aqui apresentado tem como premissa a profissionalização, que concebe o ensino como uma profissão, a qual se assenta em uma base de conhecimentos que está ancorada na prática de ensino. A profissionalização está ligada aos aspectos referentes a um conjunto de atividades profissionais, e nesse sentido envolve a autonomia, um código de ética, o reconhecimento social, bem como a própria complexidade do trabalho docente. A partir disso, a formação docente, no contexto de Quebec, é estruturada tendo como base a profissão.

A prática de ensino tem um destaque especial, pois a formação é centrada no trabalho docente, no qual o meio escolar é essencial para a formação e atuação profissional. As ações do CFIM evidenciam elementos que conferem uma política de formação docente. A importância dada aos estágios - a partir de: a) acordos estabelecidos entre a universidade e a escola; b) consideração da escola como parceira na formação dos futuros professores; c) papéis definidos para os agentes envolvidos nos processos formativos; d) promoção de condições objetivas para os professores acompanharem os estagiários; e e) formação para os professores das escolas que recebem os estagiários - constitui alguns elementos que merecem atenção, pois evidenciam uma parceria institucional de formação profissional.

É importante salientar que, no caso do Quebec, houve um grande investimento nas reformas educacionais, de modo que isso contribuiu para a formação dos professores, tanto em relação à organização do CFIM, que faz os acordos de parcerias com as instituições educacionais, quanto às formações voltadas para os professores associados.

Essa estrutura é fruto de uma política de formação docente que tem a profissionalização como elemento central, o que advém de um determinado contexto histórico e social canadense. Certamente, o Brasil tem outras características e particularidades históricas e sociais; entretanto, a experiência aqui apresentada pode inspirar reflexões sobre a 
formação de professores no Brasil, almejando um elevado nível de qualidade de formação e de ensino na educação brasileira.

\section{Referências}

ANDRÉ, M. E. D. A. Etnografia da prática escolar. 5. ed. Campinas: Papirus, 2000.

AZEVEDO, M. A. R. Os saberes de orientação dos professores formadores: desafios para ações tutoriais emancipatórias. 2009. Tese (Doutorado em Educação) - Universidade de São Paulo, São Paulo, 2009.

BORGES, C. A formação docente em educação física em Quebec: saberes, espaços, culturas e agentes. In: ENCONTRO NACIONAL DE DIDÁTICA E PRÁTICAS DE ENSINO, 14., 2008, Porto Alegre.Anais [...]. Porto Alegre: EDIPUCRS, 2008. Livro 2.

BORGES, C. La collaboration enseignante en éducation physique et à la santé. In: PORTELANCE, L.; BORGES, C.; PHARAND, J. La collaboration dans le milieu de l'éducation: dimensions pratiques et perspectives théoriques. Québec: Presses de l'Université du Quebec, 2011.p. 83-102.

BORGES, C.; PORTELANCE, L.; PHARAND, J. La collaboration entre les agents éducatifs de la prescription aux pratiques. In: BORGES, C.; PORTELANCE, L.; PHARAND, J.La collaboration dans le milieu de l'éducation: dimensions pratiques et perspectives théoriques. Québec: Presses de l’Université du Québec, 2011. p. 1-10.

BRASIL. Ministério da Educação. Conselho Nacional de Educação. Parecer CNE/CP nº 27, de 2 de outubro de 2001.Diário Oficial da União: Brasília, DF, 18 jan. 2002a. Disponível em: http://www.uems.br/proe/sec/Parecer\%20CNE-CP\%20027-2001.pdf. Acesso em: 15 maio 2021.

BRASIL. Ministério da Educação. Conselho Nacional de Educação. Parecer CNE/CP n 28,de 2 de outubro de 2001. Diário Oficial da União: Brasília, DF, 18 jan. 2002b. Disponível em: http://www.uems.br/proe/sec/Parecer\%20CNE-CP\%20028-2001.pdf. Acesso em: 15 maio 2021.

BRASIL. Lei no 13.005 , de 25 de junho de 2014. Aprova o Plano Nacional de Educação PNE e dá outras providências. Diário Oficial da União: Brasília, DF, 26 jun. 2014.

BRASIL. Ministério da Educação. Conselho Nacional de Educação. Resolução $n^{\circ} 2$, de $1^{\circ}$ de julho de 2015. Define as Diretrizes Curriculares Nacionais para a formação inicial em nível superior (cursos de licenciatura, cursos de formação pedagógica para graduados e cursos de segunda licenciatura) e para a formação continuada. Diário Oficial da União:Brasília, DF, 2 jul. 2015. Disponível em: http://portal.mec.gov.br/docman/agosto-2017-pdf/70431-res-cnecp-002-03072015-pdf/file. Acesso em: 15 maio 2021.

BRASIL. Ministério da Educação. Conselho Nacional de Educação. Resolução CNE/CP nº 2, de 20 de dezembro de 2019. Define as Diretrizes Curriculares Nacionais para a Formação 
Inicial de Professores para a Educação Básica e institui a Base Nacional Comum para a Formação Inicial de Professores da Educação Básica (BNC - Formação). Diário Oficial da União: Brasília, DF, 15 abr. 2020. Disponível em:

http://portal.mec.gov.br/docman/dezembro-2019-pdf/135951-rcp002-19/file. Acesso em: 15 maio 2021.

CONTRERAS, J. A autonomia de professores. São Paulo: Cortez, 2002.

CYRINO, M. Do acolhimento ao acompanhamento compartilhado: a construção colaborativa de uma proposta para o estágio curricular no curso de pedagogia. 2016. Tese (Doutorado em Educação) - Universidade Estadual Paulista Júlio de Mesquita Filho, Rio Claro, 2016.

CYRINO, M.; SOUZA NETO, S. O estágio curricular supervisionado na experiência brasileira e internacional. Revista Educação em Questão, Natal, v. 48, n. 34, p. 86-115, 2014.

CYRINO, M.; SOUZA NETO, S. Parceria universidade e escola no estágio curricular: um processo em constituição. Revista Diálogo Educacional, Curitiba, v. 17, n. 52, p. 661-682, 2017.

FORMOSINHO, J. A academização da formação de professores. In: FORMOSINHO, J. Formação de professores: aprendizagem profissional e acção docente. Porto: Porto, 2009.p. 73-92.

FRANCO, M. A. S. Entre a lógica da formação e a lógica das práticas: a mediação dos saberes pedagógicos. Educação e Pesquisa, São Paulo, v. 34, n. 7, p. 109-126,2008.

GATTI, B. Educação, escola e formação de professores: políticas e impasses. Educar em Revista, Curitiba, n. 50, p. 51-67,2013.

GATTI, B. Formação de professores no Brasil: características e problemas. Educação \& Sociedade, Campinas, v. 31, n. 113, p. 1355-1379, 2010.

GATTI, B. A.; BARRETO, E. S.; ANDRÉ, M. E. D. A. Políticas docentes no Brasil: um estado da arte. Brasília, DF: Unesco, 2011.

GATTI, B. et al. Professores do Brasil: novos cenários de formação. Brasília, DF: Unesco, 2019.

GAUTHIER, C.; RAYMOND, D.; MARTINET, M. A.La formation à l'enseignement: les orientations, les compétences professionnelles. Québec: MELS, Gouvernement du Québec, 2001.

GERVAIS, C. A organização dos estágios e o acompanhamento do desenvolvimento profissional dos estagiários em Quebec. Cadernos de Educação, Pelotas, n. 46, p. 23-44, 2013. 
GERVAIS, C.; DESROSIERS, P. L'école, lieu de formation d'enseignants: questions et repères pour l'accompagnement de stagiaires. Québec: Les Presses de l'Université Laval, 2005.

GIGLIO, C. M. B. Residência pedagógica como diálogo permanente entre a formação inicial e continuada de professores. In: DALBEN, A. I. L. F. et al.(org.). Convergências e tensões no campo da formação e do trabalho docente. Belo Horizonte: Autêntica, 2010. p. 13-30.

HOLMES GROUP. Tomorrow's teachers: a report of the Holmes Group. East Lansing: Holmes Group, 1986.

KARSENTI, T.; DEMERS, S.L'étude de cas. In:KARSENTI, T.; SAVOIE-ZAJC, L. La recherche en éducation: étapes et approches.3. ed. Montréal:Éditions du Renouveau Pédagogique ,2011.p. 229-252.

LUDKE, M.; ANDRÉ, M. E. D. A. Pesquisa em educação: abordagens qualitativas. São Paulo: EPU, 2001.

MAUÉS, O. C. Reformas internacionais da educação e formação de professores. Cadernos de Pesquisa, São Paulo, n. 118, p. 89-117,2003.

NÓVOA, A. Entre a formação e a profissão: ensaio sobre o modo como nos tornamos professores. Currículo sem Fronteiras, [s. l.], v. 19, n. 1, p. 198-208, 2019.

NÓVOA, A. Firmar a posição como professor, afirmar a profissão docente. Cadernos de Pesquisa, São Paulo, v. 47, n. 166, p. 1106-1133, 2017.

NÓVOA, A. Para uma formação de professores construída dentro da profissão. Revista de Educación, Madrid, n. 350, p. 203-211, 2009.

SARTI, F. M. Parceria intergeracional e formação docente. Educação em Revista, Belo Horizonte, v. 25, n. 2, p. 133-152, 2009.

SARTI, F. M. Pelos caminhos da universitarização: reflexões a partir da masterização dos IUFM franceses. Educação em Revista, Belo Horizonte, v. 29, n. 4, p. 215-243, 2013.

SOUZA NETO, S.; CYRINO, M.; BORGES, C. A profissionalização do ensino na experiência internacional e brasileira: o estágio supervisionado como protagonista. In:

SCARELI, G. (org.). Educação, culturas, políticas e práticas educacionais e suas relações com a pesquisa. Porto Alegre: Sulina, 2015. p. 285-316.

TARDIF, M. Saberes profissionais dos professores e conhecimentos universitários. Revista Brasileira de Educação, Rio de Janeiro, n. 13, p. 5-24, 2000.

TARDIF, M. A profissionalização do ensino passados trinta anos: dois passos para a frente, três para trás. Educação \& Sociedade, Campinas, v. 34, n. 123, p. 551-571, 2012.

TARDIF, M.; LESSARD, C. O trabalho docente: elementos para uma teoria da docência como profissão de interações humanas. 5. ed. Petrópolis: Vozes, 2009. 
VEDOVATTO IZA, D. F.; SOUZA NETO, S. Por uma revolução na prática de ensino: o estágio curricular supervisionado. Curitiba: CRV, 2015.

WITTORSKI, R. A contribuição da análise das práticas para a profissionalização dos professores. Cadernos de Pesquisa, São Paulo, v. 44, n. 154, p. 894-911, 2014.

Enviado em: 7/2/2021

Revisado em: 19/5/2021

Aprovado em: 20/5/2021

Publicado em: 10/1/2022 